\title{
From the Collaboration of Companies to the Interoperability of Information Systems (Concepts and Perspectives)
}

\author{
B. Faqihi, N. Daoudi, and R. Ajhoun
}

\begin{abstract}
Recent years, the companies need to work together to face the challenges. The international economic crisis and the opening of borders between countries require the creation of business groups in order to achieve a common goals: Increased coverage, increased performance, optimization and security, bargaining power,...etc. So, these systems need to communicate, collaborate and share content between them. Several domains know this revolution, among these learning. In our article, we will recall a set of concepts used since collaboration to interoperability. We will also analyze the different existing approaches in the literature as well as patterns of integration. Then we will make connections between the approaches and methods according to the use cases. Finally we will choose the appropriate approach for our context.
\end{abstract}

Index Terms-Alignment, federated approach, mapping, merging, unified approach, semantic interoperability.

\section{INTRODUCTION}

The concept of collaboration between companies is very wide. We can feel it in several scenarios for different purposes:

1) Increased coverage: Groups of partners with complementary skills.

2) Increased performance: Groups of companies positioned on the same segment,

3) Optimization and security: gatherings of suppliers from the same client,

4) Bargaining power: platform purchasing.

And all other kinds of novel networks established, casual or conjunctural [1]. The achievement of collaboration in industrial environments requires a fluidification of the structures of business (Fig. 1 a)). But we are faced with the agility constraints so critical.

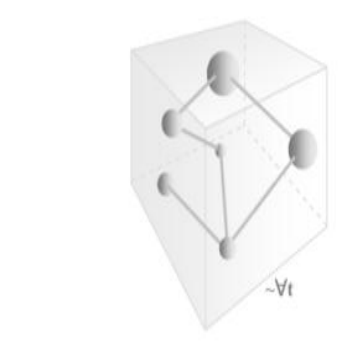

Crystallized structure

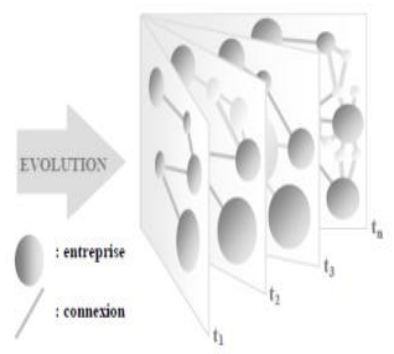

Fluid structure (strong temporal variation). Fig. 1a) From crystallized structure to a fluid structure.
Manuscript received February 10, 2014; revised April 10, 2014.

Moulay Brahim Faqihi is with the University Mohammed V, Morocco (e-mail: brahimfaqihi@ hotmail.com).
Yesterday, the quality of collaboration between business, was based on the robustness of the fixed connections, today it rests on the ability of firms to evolve and connect them effectively and fast way.

\section{FROM COLLABORATION TO INTEROPERABILITY}

According to [2], the concept of collaboration can be studied from different aspects :

1) Temporal: It is opportunistic, occasional, periodic, systematic, permanent?

2) Relationnel: she relates competitors, complementary organizations, customer and his suppliers, a combination of these relations?

3) Topologique: it is structured in a star network, point to point on a linear chain or a combination of these structures?

4) Intimité: what is the criticality or information power or functions shared by the partners? Etc.

In the literature, there are several ways to decline the collaboration. According to [3], This description is divided into four levels:

1) Communication: The data exchange This is pure and simple data exchange. At this stage, companies must communicate, exchange and share information to maximize their individual operation.

2) Coordination: sharing and synchronization of tasks. Indeed, the absence of common purpose makes the design of a collaborative process difficult or impossible.

3) Cooperation: pursuit of a common goal. The purpose of the business network is to pursue a collective goal. This requires the establishment of a collective process that members must define and integrate.

4) Integration: transparent membership to the same entity. Whether virtual or real. The three levels mentioned above are inherent because companies are integrated into a single entity.

\section{LEVELS OF COLLABORATIVE MATURITY}

A summary of the standard IEC TC 65/290/DC [4] on the evaluation of the compatibility of the companies is described [5]. By comparing of these results with the four levels mentioned above, we can deduct the following levels of collaborative maturity:

1) Interconnecting: The initial ability of firms to have communication interfaces allowing asynchronous communication. 
2) Open: The ability to share features, services and to be open his skills outwards but also to access external features that are available to them. Exchanges must be synchronous [6].

3) Federated: ability to work in a collective behavior. This requires knowledge of internal processes for integrate to the collaborative process. (Certifications de type ISO ou Capacity Maturity Model).

4) Interoperable: The ability to immerse themselves within a larger entity and to become an active component able to participate in behavior in which it is melted. This amounts to fluidize: the flow of data, application management and process execution. Interoperability is seen as a means for achieving integration.

For this fourth level (Interoperable), which interest us, it is noted that this capacity is characterized by the level of effort required for businesses to reach. Indeed, the achievement of interoperability can be achieved by a business overhaul thorough in the absence of standardization in relation to standards ensuring their integration capacity. However, this vision "totalitarian" or "radical" is not the only one. We can reach enterprise interoperability by limiting required effort using ontologies.

\section{CHARACTERIZATION OF ENTERPRISE INTEROPERABILITY}

We will describe in this section, levels that characterize the concept of interoperability. Indeed, firms differ in terms of culture, language, art, technology,...etc. Several research studies have focused on the framework that defines these levels.

Among these frameworks, we can mention:

1) IDEAS (Interoperability Development for Enterprise Applications and Software, IST-2001-37368) [7]: which is defined as an approach for the collection of visions and challenges of research on interoperability.

2) AIF (Athena Interoperability Framework) [8], [9] adopt a holistic approach that allows understanding and analysis of requirement of interoperability.

3) EIF (European Interoperability Framework) [10] structure guidelines for interoperability between European administrations, and between the administrations and citizens.

The analysis allows inferring that these three frameworks converge towards the consideration of three levels: Art, Semantic et Technical.

The information system plays an important role in becoming an enterprise interoperable. To achieving interoperability between companies, we should assess the degree of its information system to be interoperable. So we will focus on the semantic aspect of interoperability between information systems of companies.

More general, semantics refers to the meaning of the various components of an information system. The meaning or significance of a component may vary from one system to another [11]. We must therefore ensure that the information exchanged have the same interpretation between all systems. Semantic interoperability is defined according F. Vernadat [12], as "the ability to share, synchronize and aggregate the information in heterogeneous information systems...". It is the ability to share information (processes, data and application) with another information system. Companies wishing to be semantically interoperable must clearly describe and define their systems to be able to share information with other companies by keeping the same meaning. [13], For him, the semantic conflicts "affect not only the data, but can also affect other layers of integration including the functions and processes...". This means that the semantic interoperability of information systems, can be decomposed into:

1) Semantic interoperability of process: It is the ability to interoperate processes different areas.

2) Semantic interoperability of data: Pooling data for describe differents repositories.

3) Semantic interoperability of applications: Is pooling proposed functions by the corporate information systems. Because we can see a difficulty in interpreting a function or data offered by an application. The semantic services oriented approach [13] is an application of this type of interoperability.

Among the semantic conflicts: the disambiguation where the same name covers several concepts, the synonymy where several names cover the same concept. To overcome it, we must appeal to mediation mechanisms to converge the different semantic interpretations of the elements of the information system. The design of this mediation should be based on a repository able to unambiguously identify the meaning and scope of each element used by SI wishing ensures such interoperability.

It is worth mentioning here the nuance between interoperability, cooperation and collaboration. These last two are specifically related to the combination of a number of resources for a common purpose [14]. This is seen especially in the context of an industrial process. Conversely, interoperability is essential to ensure the achievement of objectives set for collaboration or cooperation. It isn't a goal sought by companies.

\section{APPROACH TO THE INTEROPERABILITY OF INFORMATION SYSTEMS}

The interoperability between information systems is not easy to achieve. In this area, the work analysis of INTEROP [15]: European Network of Excellence shows that there are two approaches:

1) An approach to unification and standardization: In which, it must agree to unify the presentation the data, processes and applications. The same applies to tools, methods and strategies to facilitate the interoperability of informations systems (IS).

2) An approach of "no standardization": The collaboration is done without worrying the heterogeneity and by keeping data formats, process models, existing applications and hardware. It is collaboration without special effort on the part of partners.

For systems not yet designed, the first approach is the most suitable. However, in the case of existing systems that have a historical, and that is the majority of cases, it appears that the second approach is more realistic, more pragmatic and more consistent with the principles of interoperability. In addition, 
the unification approach is very expensive, by the approach against "no standardization" is very attractive because it offers companies more freedom. The most concrete example is the assembly of the United Nations.

\section{SEMANTIC INTEROPERABILITY BETWEEN IS}

Solving the problem of semantic interoperability amounts to solving semantic conflicts during exchange. The objective is to have a similar element interpretations. So we should have description and formalism of these elements to facilitate the sharing while keeping the same meaning. We must use "a set of data that characterize other data to enable research, management and conversion" which means meta data. The two solutions based on the use of metadata are: ontology and standardization.

\section{A. Ontology}

In the literature, there are several definitions. It defines the common vocabulary for various entities that want to share information in a specific area. It's "a formal explicit description of concepts in a domain of discourse". That means, it allows two entities exchange, eliminate the semantic conflicts and improve communication and the sharing of meaning.

\section{B. Standardisation}

Based on metadatas, standardization of structures allows to describe content. It is important for ensure sharing of the content meaning exchanged. It is strongly recommended, inter alia, in the following areas: health information system, government management, education, etc. So the common structure and the metadata that describes the content exchanged, allows to heterogeneous entities the opportunity to share the meaning during exchange according to standardization models identical.

\section{SEMANTIC INTEROPERABILITY AND ONTOLOGIES}

Solving the problem of semantic interoperability amounts to solving semantic conflicts during exchange. The objective is to have a similar element interpretations. So we should have description and formalism of these elements to facilitate the sharing while keeping the same meaning. We must use "a set of data that characterize other data to enable research, management and conversion" which means meta data. The two solutions based on the use of metadata are: ontology and standardization.

Interoperability brings two major problems, the syntactic and semantic conflicts. These two types of conflicts require characterize syntactic interoperability and semantic interoperability [16]. Ensure semantic interoperability between information systems is to ensure it be achieved between ontologies that represent these information systems. In the literature[17]-[19], several solutions projects were presented.

They can be summarized into four broad categories:

1) Mapping of ontologies: Whose objective is the representation of mappings between ontologies? This allows, for example, interrogating heterogeneous knowledge bases using a common interface or converting data between different representations.

2) Merging of ontologies: It allows create a new ontology, named the merged ontology by capturing the knowledge of the origin ontologies. The challenge then is to ensure that all correspondences and differences between ontologies are properly taken into account in the resulting ontology.

3) Alignment of ontologies: The objective is to find correspondences between ontologies.

4) Integration of ontologies: It is a process of building a new ontology. Il n'est pas nécessairement destiné à remplacer les autres. They may continue to be used, to be updated and evolve, etc. These ontologies can be related.

\section{Mapping}

The most relevant definition is probably of Noy for which the mapping of ontologies is a process that specifies a semantic convergence between different ontologies to extract correspondences between certain entities [20]. It isn't a creation of a new ontology. This process applies, inter alia, in the following areas: information retrieval, e-commerce, medicine, etc., which have the ontologies with a big size and which should be reused.

These mappings are expressed by introducing axioms formulated in a specific language.

Three main phases can be distinguished in these processes (Fig. 1 b)):

1) Discovery of the mapping;

2) Representation of the mapping;

3) Operation/Implementation of the mapping.

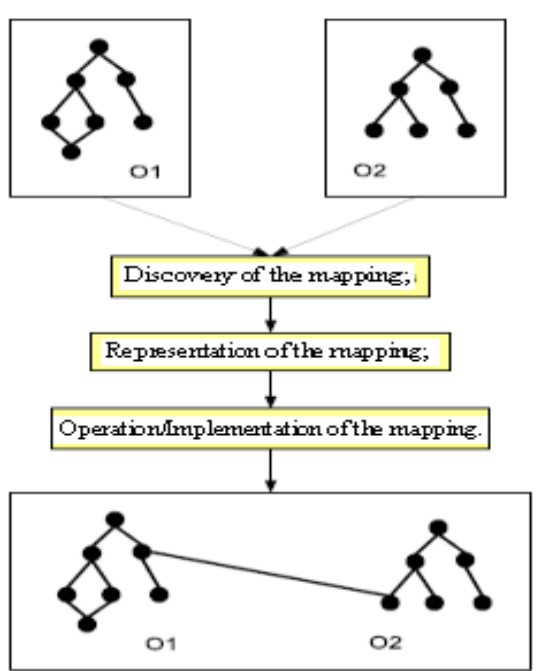

Fig. 1 b). Mapping of ontologie.

The tools and methods most used in this category are: MAFRA [21], IF-Map [22], RDFT [23], C-OWL [24] and OntoMap [25].

\section{Merging}

[26] gives the following definition of merging ontologies : "Ontology merging is the process of generating a single, coherent ontology from two or more existing and different ontologies related to the same subject". Merging ontologies is the creation of a new ontology from two or more ontologies. The resulting ontology unifies and replaces the original ontologies (Fig. 2). 
This definition does not specify how the resulting ontology is connected to the original ontologies for leave open the problem of selecting the fusion method. The most common approaches use the union or intersection. In the union approach, the resulting ontology contains the union of features from the original ontologies and assumes that the differences in representation of the same concept were resolved. In the approach of intersection type, resulting ontology contains only the common parts of the original ontologies.

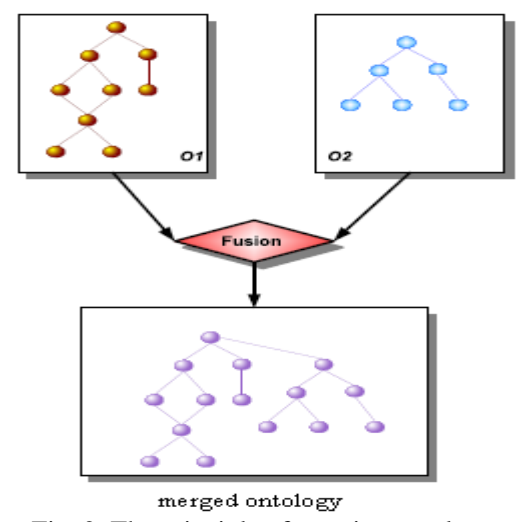

Fig. 2. The principle of merging ontology.

Several approaches to implement the merger of ontologies have been proposed such as: PROMPT [27], CHIMAERA [28], FCA-Merge [29] and OntoMerge [30].

\section{E. Alignment}

The alignment of ontologies allows establishing semantic relationships between concepts of ontologies, as shown in the definition of Namyoun [26]: "Ontology alignment is the task of creating links between two original ontologies. Ontology alignment is made if the sources become consistent with each other but are kept separate. Ontology alignment ismade when they usually have complementary domains". Ontology matching is a process of finding matches between two sources of ontologies. It is generally described as an application of the operator MATCH [31], whose input is constituted by a set of ontologies and the output is formed by correspondences between these ontologies. (Fig. 3).

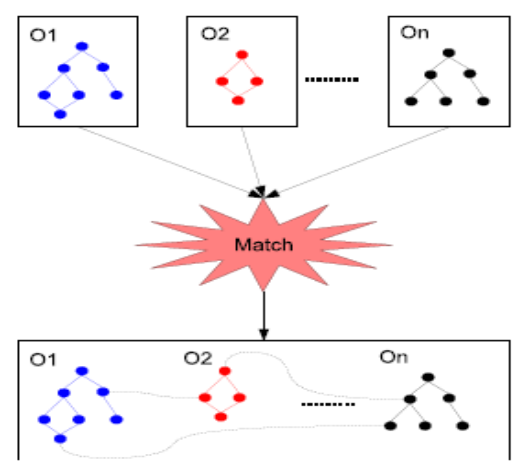

Fig. 3. The operator match.

In the literature, there are several algorithms that implement this operator. These algorithms are usually grouped into four classes. We find: Matching based on schema, matching based on instance, matching based on element level, and matching based on level of structure.

A matcher based on the scheme takes into account different aspects of concepts and relationships in ontologies and uses similarity measures to determine the correspondence. Instances belonging to concepts of different ontologies are compared in order to find similarities between the concepts. The "element level matcher" compares the properties of a particular concept and a particular relationship (eg to find similarities by name). The "structure level matcher" compares the structure, that is to say, the hierarchy of concepts in order to find similarities [32], [33]. According Ehrig, these "matchers" may also be combined [34].

Among the ontology alignment approaches, there are: Anchor-PROMPT [32], GLUE [35], [33], QOM [34] and ASCO [36].

\section{F. Approaches to Semantic Interoperability}

In the literature, there are three main approaches (See Table I) [37]: integrated approach federated approach and unified approach. We will detail them in the following paragraphs:

\section{1) Integrated approach}

Also called, a global ontology, a unique ontology or a simple ontology. Its principle is to get agreement with a single ontology, finding a consensus on vocabulary, the semantics, the viewpoint, etc. The other data sources (fig. 1 b)) must be connected to this ontology. It is a fusion of all ontologies into one. This approach is used when we have a global ontology with a shared vocabulary, or when multiple ontologies covering the same area and having the same goal with a similar granularity. By cons, it has limitations when the ontology to be integrated contains heterogeneous data and evolve independently. It is mandatory in this case, to maintain global ontology and the other data sources regularly.

\section{2) Federated approach}

Also named distributed mediation or multiples ontologies. In this case, each source is described by its own ontology and each ontology is completely independent of the other. The advantage of this approach is that the definition of each source ontology can be set apart from others. A large flexibility is ensured because ontologies can evolve independently and can undergo to frequent updates. In addition, deleting ontology doesn't block the overall system. Just remove the links concerned with the ontology. However, the lack of a common vocabulary for federated approach makes the comparison of ontologies sources very difficult. To overcome this problem, a mapping formalism between ontology is highly recommended, it identifies the semantic links and connections between different source ontology. This action is extremely difficult to achieve because many problems will appear: the semantic heterogeneity, the synonymy, The homonymy and especially the ambiguity due to the lack of information [33].

\section{3) Unified approach}

The unified approach, also called "hybrid" combines the two previous approaches. It involves first identifying links (Fig. 3) between different local ontologies of each source. Then, it establishes correspondences between different ontologies and one upper ontology named global ontology. Like the previous approach, the ontology and its source can 
evolve independently. Just update the correspondence of ontologies involved in evolution. This is a very interesting approach if designing of ontologies is based on a standard. The authors [34] recommend that all local ontologies should be described based on a common shared vocabulary that can itself be ontology. This dictionary must contain the basic terms of a given domain. Other fairly complex terms may arise from the basic terms through dedicated operators. The advantage of this approach is that it's open and scalable. Other new sources can be added without modifying the common vocabulary. In addition, ontologies use a common language although their sources can be independent.

\begin{tabular}{|l|l|l|}
\multicolumn{4}{|c|}{ TABLE I: THE SUMMARY TABLE } \\
\hline Approach & \multicolumn{1}{|c|}{ Advantages } & \multicolumn{1}{c|}{ Limits } \\
\hline integrated & $\begin{array}{l}\text { Interesting when you have a } \\
\text { global ontology providing a } \\
\text { shared vocabulary for the } \\
\text { semantic specification or } \\
\text { when multiple ontologies } \\
\text { covering the same domain. }\end{array}$ & $\begin{array}{l}\text { To avoid when } \\
\text { ontologies are } \\
\text { heterogeneous and } \\
\text { evolving } \\
\text { independently. }\end{array}$ \\
\hline federated & $\begin{array}{l}\text { Each ontology can be defined } \\
\text { without considering other } \\
\text { ontologies. It allows } \\
\text { flexibility in using ontologies } \\
\text { which evolve independently. }\end{array}$ & $\begin{array}{l}\text { Very difficult to } \\
\text { compare different } \\
\text { ontology sources. It } \\
\text { grows to think about } \\
\text { the problem of } \\
\text { semantic } \\
\text { interoperability. }\end{array}$ \\
\hline unified & $\begin{array}{l}\text { Interesting if the ontology } \\
\text { conform to a certain standard. } \\
\text { New ontologies can be added } \\
\text { without the need to change the } \\
\text { vocabulary. }\end{array}$ & \\
\hline
\end{tabular}

Our context is more consistent with the federated approach. Indeed, in the field of learning, universities do not have a common vocabulary for the allocation of a given diploma. This is a problem of equivalence of diplomas. In addition, it creates more and more college graduations, which are known and recognized in the economic environment of the university... Therefore, the establishment of correspondence is increasingly difficult. The approach that fits our situation should allow to universities to create freely diplomas and grow in their regions. It shall also provide increasingly using standards. So, we propose the creation of a global ontology that each university should first refer when creating its diplomas. Indeed, the problem is much more than correspondences. We have two candidates from two different institutions. The first graduated in three years. The second received the same degree in four years. They had a review of access to public office. In cases where they were selected, what will their administrative situations? From what is mentioned above, we note that there is a strong liaison between the approaches and methods of integration. We will be based on use cases, for identify the feasible modes for each approach. For the federated approach, we do not have a comprehensive ontology that serves as a reference for local ontologies $\mathrm{O} 1$ and $\mathrm{O} 2$, relating respectively to data sources $\mathrm{S} 1$ and S2. But if it is created it will respond perfectly to our problem. The unified approach, in turn, requires the existence of a global ontology. Something that does not exist for the community of Moroccan universities. Admittedly, universities tend to standardize the terminology used. Especially to address the problems related to the equivalence of diplomas. But they are far from having single reference ontology. To exchange between systems S1 and S2, we will be in one of the approaches: integrated, federated or hybrid. In the federated approach is that we have a global ontology? In general, we aren't in this case. Whether $\mathrm{O} 1$ and $\mathrm{O} 2$ : two different ontologies. The case of the hybrid approach is very close to the unified approach. Indeed, in the absence of reference ontology, its implementation is quite difficult.

The following Table II summarizes the correspondence between the approaches and the possible mode of integration according to the use cases:

TABLE II: CORRESPONDENCE BETWEEN THE APPROACHES AND THE POSSIBLE MODE OF INTEGRATION

\begin{tabular}{|c|c|c|c|}
\hline Approach & $\begin{array}{l}\text { Integration } \\
\text { Mode }\end{array}$ & Some technical & Use Cases \\
\hline integrated & $\begin{array}{l}\text { Integration and } \\
\text { fusion: since } \\
\text { these two modes } \\
\text { provide the } \\
\text { implementation } \\
\text { of ontology by } \\
\text { gathering } \\
\text { knowledge of two } \\
\text { or more existing } \\
\text { ontologies. }\end{array}$ & $\begin{array}{l}\text { CHIMERAE, } \\
\text { PROMPT. } \\
\text { FCA-MERGE, } \\
\text { SMART. }\end{array}$ & $\begin{array}{l}\text { It is interesting if } \\
\text { we have multiple } \\
\text { ontologies } \\
\text { covering the same } \\
\text { domain. } \\
\text { I think it is close to } \\
\text { our problem since } \\
\text { each university } \\
\text { has its own } \\
\text { ontology and all of } \\
\text { the ontologies } \\
\text { cover the same } \\
\text { area }\end{array}$ \\
\hline federated & $\begin{array}{l}\text { Mapping or } \\
\text { alignment: since } \\
\text { each ontology is } \\
\text { defined without } \\
\text { considering other } \\
\text { ontologies. }\end{array}$ & $\begin{array}{l}\text { Similarity } \\
\text { Flooding, } \\
\text { Anchor-prompt, } \\
\text { GLUE, MAFRA, } \\
\text { S-MATCH, } \\
\text { ONTOMAP, } \\
\text { MOMIS. } \\
\text { ONION }\end{array}$ & $\begin{array}{l}\text { Most appropriate } \\
\text { to our context that } \\
\text { is the learning } \\
\text { field because the } \\
\text { addition or } \\
\text { removal of } \\
\text { ontology or a } \\
\text { partnership with a } \\
\text { university does not } \\
\text { influence the } \\
\text { general } \\
\text { agreements. }\end{array}$ \\
\hline unified & $\begin{array}{l}\text { Integration: since } \\
\text { it is assumed that } \\
\text { there is a global } \\
\text { ontology at which } \\
\text { the local } \\
\text { ontologies will } \\
\text { refer when } \\
\text { creating. }\end{array}$ & $\begin{array}{l}\text { CHIMERAE, } \\
\text { PROMPT, } \\
\text { FCA-MERGE, } \\
\text { SMART. }\end{array}$ & $\begin{array}{l}\text { Far from being } \\
\text { suitable to our } \\
\text { context since it } \\
\text { assumes that the } \\
\text { creation of local } \\
\text { ontologies is based } \\
\text { on the standard } \\
\text { vocabularies and } \\
\text { shared. This is not } \\
\text { the case for the } \\
\text { ontologies of our } \\
\text { universities. }\end{array}$ \\
\hline
\end{tabular}

According summary table, it seems clear that for our context where universities are regarded as remote information systems, which are represented by their ontologies must fit one of the following approaches: integrated or federated. Though that I prefer federated approach because it allows more flexibility. Thus, each university can develop his ontology in its own way. It can also establish specific diplomas, determine modules, the learners qualification and teachers qualification who will be affected. All this independently of the other ontologies. This approach also allows the use of ontologies that can evolve independently and can be updates frequently. Better yet, this approach is not blocking. Because, if an ontology or an university wants to break exchange, sharing and collaboration, it has no impact on other ontologies or other 
universities.

\section{CONCLUSION}

In this article, we try to clarify the concepts used in the framework of the collaboration. Initially we treated the enterprise level, the types of collaborations as well as its levels of maturity. Then we discussed the existing approaches in the literatures which tackle our problems. Then after we presented some existing techniques. At the end, we conducted an analysis to determine the appropriate method in our context which is the interoperability of information systems of universities.

\section{REFERENCES}

[1] B. Faqihi, N. Daoudi, and R. Ajhoun, "Semantic interoperability in the d-learning in the era of cloud computing: Simplicity or complexity," International Conference Learning ICL, Kazan, Republic of Tatarstan, Russia, 25-27 September 2013.

[2] C. L. Villareal, "Contribution au Pilotage Des Projets PartagEs Par DEs PME en Groupement BasEe Sur la Gestion Des Risques," thèse de doctorat, Ecole des mines d'Albi-Carmaux, 2005.

[3] L. Bouzguenda, "Coordination Multi-Agents Pour le Workflow Inter-Organisationnel Lâche," thèse de doctorat, IRIT, 2006.

[4] IEC 62390, "Common automation device," Profile Guideline, IEC TC 65/290/DC Device Profile Guideline, 2002, TC65: Industrial Process Measurement and Control, IEC TR 62390, IEC, GENEVA, Switzerland, 2005.

[5] K. Kosanke, "ISO Standars for Interoperability: A comparison, INTEROP-ESA'05," in Proc. the First International Conference on Interoperability of Entreprise Software and Applications (IFIP/ACM SIGAPP INTEROP-ESA'), 2005.

[6] H. Pingaud, "Logistiques et Technologies de L'information et de la Communication : Les Guides Experts," WEKA, p. 100, 2003.

[7] IDEAS, "A Gap Analysis -Required Activities in Research, Technology Andstandardisation to Close the RTS Gap- Roadmaps and Recommendations on RTS Activates," IDEAS, Deliverables, 2003.

[8] ATHENA, "D.A1.3.1: Report on methodology description and guidelines definition Version 1.0," ATHENA Integrated Project, deliverable D.A1.3.1, March 2005.

[9] A. J. Berre, B. Elveaster, N. Figay, C. Guglielmina, S. G. Johnsen, D. Karlsen, T. Knothe, and S. Lippe, The ATHENA Interoperability Framework, Enterprise Interoperability: New challenges and approaches II, Springer edition, 2007.

[10] European Interoperability Framework. (Feb. 2004). White Paper. Brussels. [Online]. Available: http://www.comptia.org.

[11] N. Daoudi, "MADAR learning: Environnement d'apprentissage interopérable entre le e-learning et le m-learning," Thèse de Doctorat en Informatique, École Nationale Supérieure d'Informatique et d'Analyse des Systèmes, Maroc, 2009.

[12] F. Vernadat, "Interoperable Enterprise Systems: Architecture and Methods," presented at IFAC/INCOM conference on plenary lecture, Saint-Etienne, May 2006.

[13] S. Izza, "Intégration des systèmes d'information industriels, une approche flexible basée sur les services sémantiques," thèse de doctorat, Ecole des Mines de Saint-Étienne, 2006.

[14] S. Blanc, "Contribution a la caractérisation et a l'évaluation de l'interopérabilité pour les entreprises collaboratives," Thèse de Doctorat, L'UNIVERSITE BORDEAUX 1, France, Décembre 2006.

[15] D. Konstantas, J. P. Bourrières, M. Léonard, and N. Boudjlida, "Preface de: INteroperability of entreprise software and application," Actes de INTEROP-ESA'05, Genève, Suisse, Springer-Verlag, p. v-vi, 21-25 février 2005 .

[16] F. Jouanot, "Un modèle sémantique pour l'interopérabilité de systèmes d'information," INFORSID, pp. 347-364, 2000.

[17] J. de Bruijn, M. Ehrig, C. Feier, F. Martin-Recuerda, F. Scharffe, and Mortiz Weiten, "Semantic Web Technologies, trends and research in ontology-based systems," Chapter Ontology Mediation, Merging, and Aligning, pp. 95-113. Wiley, 2006.

[18] N. Mellal, "Réalisation de l'interopérabilité sémantique des systèmes, basée sur les ontologies et les flux d'information," Thèse de Doctorat, Université de SAVOIE, France, Décembre 2007.
[19] A. Elbyed, "Romie, une approche d'alignement d'ontologies à base d'instances," Thèse de Doctorat, L'Universite D'Evry-Val D'Essonne, France, Octobre 2009.

[20] N. Noy, "Semantic integration: a survey of ontology-based approaches," SIGMOD Rec., vol. 33, no. 4, pp. 65-70, 2004.

[21] A. Maedche, B. Motik, N. Silva, and R. Volz, "Mafra - A Mapping Framework for Distributed Ontologies," in Proc. 13th European Conference on Knowledge Engineering and Knowledge Management (EKAW), Siquenca, Spain, 2002.

[22] Y. Kalfoglou and M. Schorlemmer, "If-map: an ontology mapping method based on information flow theory," Journal on Data Semantics, vol. 1, no. 1, pp. 98-127, October 2003.

[23] B. Omelayenko, "Rdft: A mapping meta-ontology for web service integration," pp. 137-153, 2003.

[24] P. Bouquet, F. Giunchiglia, F. van Harmelen, L. Serafini, and H. Stuckenschmidt, "Contextualizing ontologiesstar, open," Web Semantic: Science, Services and Agents on the World Wide Web, vol. 1, no. 4, pp. 325-343, 2004.

[25] J. Angele and H.-P. Schnurr, "Do not use this gear with a switching lever! Automotive industry experience with semantic guides," GI Jahrestagung, vol. 1, pp. 48-52, 2005.

[26] C. Namyoun, I. L. Song, and Han Hyoil, "A survey on ontology mapping," Sigmod Rec., vol. 35, no. 3, pp. 34-41, September 2006.

[27] N. F. Noy and M. Musen, Prompt: Algorithm and Tool for Automated Ontology Merging and Alignment, pp. 450-455, 2000.

[28] D. Mcguinness, R. Fikes, J. Rice, and S. Wilder, The Chimaera Ontology Environment, AAAI Press / The MIT Press, pp. 1123-1124.

[29] G. Stumme and A. Maedche, "Fca-merge: Bottom-up merging of ontologies," IJCAI, pp. 225-234, 2001.

[30] D. Dou, D. Mcdermott, and Q. I. Peishen, Ontology Translation by Ontology Merging and Automated Reasoning, 2002.

[31] E. Rahm and P. Bernstein, "A survey of approaches to automatic schema matching," The VLDB Journal, vol. 10, no. 4, pp. 334-350, 2001.

[32] N. Noy and M. Musen, Anchor-Prompt: Using Non-Local Context for Semantic Matching, 2000.

[33] F. Giunchiglia, P. Shvaiko, and M. Yatskevich, "S-match: An algorithm and an implementation of semantic matching," in Y. Kalfoglou, M. Schorlemmer, A. Sheth, S. Staab, and M. Uschold, ed., Semantic Interoperability and Integration, number 04391 in Dagstuhl Seminar Proceedings, Internationales Begegnungs und Forschungszentrum fuer Informatik (IBFI), Schloss Dagstuhl, Germany, 2005.

[34] M. Ehrig and S. Staab, "Qom quick ontology mapping," in Proc. International SemanticWeb Conference (ISWC 2004), Japan, November 2004

[35] A. H. Doan, J. Madhavan, P. Domingos, and A. Halevy, Ontology Matching: A Machine Learning Approach, 2003.

[36] B. L. E. Thanh, R. Dieng-Kuntz, and F. gandon, "On ontology matching problems - for building a corporate semantic web in a multi-communities organization," in Proc. ICEIS, vol. 4, pp. 236-243, 2004.

[37] B. Faqihi, N. Daoudi, and R. Ajhoun, "Towards the implementation of semantic interoperability of information systems via technique of matching: Issue and prospective," in Proc. 7th International Conference on Interactive Mobile and Computer Aided Learning IMCL, Aman, Jordanie, November 2012.

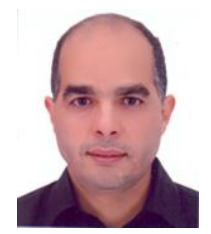

B. Faqihi was born in 1973 in Morocco. In 2004, he got his depth graduate degree in software engineering and advanced technology of information at Engineers Mohammedia School in Rabat. Her thesis is entitled: "Aid tools to indexing: Canonical form and business concepts. In 2009, he got his master specializing in human resources management at the Higher Institute of Commerce and Business Administration in Casablanca. Her thesis is entitled "Towards the establishment of a staff appraisal system of company." He has published the following articles: "Towards the implementation of semantic interoperability of information systems via technique of matching: Issue and prospective", Amman-Jordan, 7th International Conference on Interactive Mobile and Computer Aided Learning Princess Sumaya University for Technology 6-8 November 2012.

Between 2005 and 2009, he was temporary teacher of computer science at the University Hassan II in Casablanca. Since 2010, he is an active member on research structure : learning and research in mobile age. He is a Phd Student at the fourth year. His research topic is the semantic interoperability between the learning information systems in cloud era. 


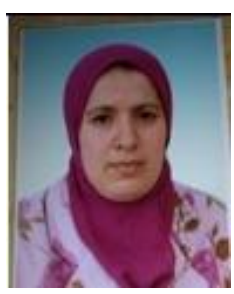

N. Daoudi was born in 1976 in Morocco. She is $\mathrm{PhD}$ at ENSIAS. Rabat, Morocco. The thesis entitled "MADAR Learning: interoperable environment between E-learning and M-learning." 2009. Diploma of Higher Studies. EMI, Rabat, Morocco. 2004 Engineer Degree at INSEA, Rabat, Morocco. 1999. Professor assistant in ESI since December 2000.

MADAR learning: an interoperable environment for E\&M learning. IEEE Engineering Education 2010. The Future of Global Learning in Engineering Education 14-16 April 2010 in Madrid/Spain.

Tutoring 2.0: How to improve tutoring system by using web mining? INTED: the international technology, education and development conference, Valencia, Spain, March, 2013

Role of Model of excellence to improve d-learning projects. Else International scientific conference elerning software for education, Bucharest, April 25th - 26th, 2013.
How to Promote Learning in African Countries? Open d-learning System Based on an Open Content. IJET: International Journal of Emerging Technologies in Learning (iJET) vol $8 \mathrm{~N}^{\circ} 4$. August 2013.

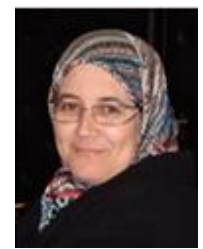

R. Ajhoun was born in Morocco. She got computer science engineer degree from EMI School (Mohammadia School of Engineering). PhD in computer science and e-learning at University of Mohammed V. Prof. Ajhoun has published articles and books about E-learning and teaches at the ENSIAS School. Prof. Ajhoun is a senior member of IEEE, director of MSIWeb Master at ENSIAS, director of the E-learning Center a University of Mohammed V, director of LeRMA (Learning and Research in Mobile Age) team. She has founded the GUIDE (Global University In Distance Education) association and she was a director of e-NGN (E-Next Generation Networks) association. 